\title{
Volume Overload and Pressure Overload due to Left-to- Right Shunt-Induced Myocardial Injury - Evaluation Using a Highly Sensitive Cardiac Troponin-I Assay in Children With Congenital Heart Disease -
}

Masaya Sugimoto, MD, PhD; Kei Ota, MD; Aya Kajihama, MD; Kouichi Nakau, MD; Hiromi Manabe, MD; Hiroki Kajino, MD, PhD

\begin{abstract}
Background: Cardiac troponin I (cTnl) is currently considered to be the most sensitive and specific biochemical marker of acute coronary syndrome and acute myocardial infarction. However, few reports have described the use of cTnl assays for evaluating abnormal hemodynamic load in children with congenital heart disease (CHD). It was hypothesized that significant hemodynamic overload due to a left-to-right shunt induces myocardial injury.
\end{abstract}

Methods and Results: A highly sensitive cTnl assay was used to measure the serum cTnl levels in 30 children with atrial septal defect (ASD), 32 children with ventricular septal defect (VSD), and 350 healthy children. Cardiac catheterization was performed in the children with ASD and VSD to determine the ratio of pulmonary to systemic blood flow, the ratio of pulmonary to systemic arterial pressure (Pp/Ps), the pulmonary vascular resistance index, and the right and left ventricular end-diastolic volume. Serum cTnl levels in both the ASD and VSD children were significantly higher than those in healthy children $(\mathrm{P}<0.05$ and $\mathrm{P}<0.01$, respectively). Furthermore, serum cTnl levels significantly correlated with $\mathrm{Pp} / \mathrm{Ps}(\mathrm{r}=0.745, \mathrm{P}<0.001)$ in VSD children.

Conclusions: Significant volume and pressure overload due to a left-to-right shunt induce myocardial injury and might eventually cause irreversible myocardial remodeling in children with CHD. The serum cTnl level is a useful biomarker for evaluating myocardial damage associated with pulmonary hypertension in VSD children. (Circ $J$ 2011; 75: 2213-2219)

Key Words: Congenital heart disease; Myocardial injury; Pulmonary hypertension; Troponin I

C ardiac troponins $\mathrm{I}(\mathrm{cTnI})$ and $\mathrm{T}(\mathrm{cTnT})$ are currently considered to be the most sensitive and specific biochemical markers of acute coronary syndrome and acute myocardial infarction (AMI). ${ }^{1,2} \mathrm{cTnI}$ is found in the atrial and ventricular walls and contains an immunologically distinct $\mathrm{N}$-terminus of the amino acid chain. ${ }^{3} \mathrm{cTnI}$ is released into the circulation in response to ischemic and non-ischemic cardiac injury. ${ }^{4}$ An assay for serum cTnI that facilitates the measurement of clinically-relevant cTnI levels is useful for the diagnosis of myocardial injury in adults. ${ }^{3,5-7}$ In 2000, the European Society of Cardiology and the American College of Cardiology also advocated that a serum troponin level that exceeded the $99^{\text {th }}$ percentile of a reference population is a specific biochemical marker of AMI. ${ }^{8}$ Moreover, elevated serum troponin levels have been reported in several cohorts of patients with heart failure, and the magnitude of the elevation correlated with the severity of the heart disease. ${ }^{9}$

\section{Editorial p 2056}

The first-generation troponin assay has some limitations. These limitations include antibody specificity, assay imprecision, lack of standardization, and the relatively late increase in circulating troponin levels after the onset of ischemia. Recently, a second-generation cTnI assay (Centaur TnI-Ultra assay) has become available. ${ }^{10-12}$ This group of sensitive troponin assays might further enhance the accuracy of the diagnosis of myocardial ischemia, and could therefore offer improved diagnostic sensitivity and specificity, even in patients presenting early after the onset of chest pain. ${ }^{13,14}$

In congenital heart disease (CHD), anatomical anomalies of the heart are generally associated with abnormal hemodynamic load and neurohumoral activation. Brain natriuretic peptide (BNP) and its N-terminal prohormone fragment (NT-

Received December 5, 2010; revised manuscript received March 25, 2011; accepted April 18, 2011; released online July 14, 2011

Time for primary review: 31 days

Department of Pediatrics, Asahikawa Medical University, Asahikawa, Japan

Mailing address: Masaya Sugimoto, MD, PhD, Department of Pediatrics, Asahikawa Medical University, 2-1-1-1 Midorigaoka, Higashi,

Asahikawa 078-8510, Japan. E-mail: masaya5p@asahikawa-med.ac.jp

ISSN-1346-9843 doi:10.1253/circj.CJ-10-1211

All rights are reserved to the Japanese Circulation Society. For permissions, please e-mail: cj@j-circ.or.jp 


\begin{tabular}{|c|c|c|c|}
\hline & \multirow{2}{*}{ Healthy group } & \multicolumn{2}{|c|}{ CHD } \\
\hline & & ASD group & VSD group \\
\hline $\mathbf{N}$ & 350 & 30 & 32 \\
\hline Age (years) & $3.9 \pm 3.7$ & $3.4 \pm 4.2$ & $1.0 \pm 1.3^{*}$ \\
\hline Gender, male & $174(49.7 \%)$ & $12(40.0 \%)$ & $13(40.6 \%)$ \\
\hline NT-proBNP (pg/ml) & $98.8 \pm 92.8$ & $304.1 \pm 370.3$ & $1,181.0 \pm 1761.9^{*}$ \\
\hline \multicolumn{4}{|l|}{ Medications } \\
\hline Diuretics (\%) & & $6(20.0 \%)$ & 27 (84.3\%) \\
\hline \multicolumn{4}{|l|}{ Hemodynamics } \\
\hline Qp/Qs & & $2.3 \pm 1.0$ & $2.4 \pm 1.1$ \\
\hline $\mathrm{Pp} / \mathrm{Ps}$ & & $0.3 \pm 0.1$ & $0.8 \pm 0.3^{\star \star}$ \\
\hline Rpl & & $1.0 \pm 0.6$ & $2.2 \pm 1.2^{\star \star}$ \\
\hline \%RVEDV & & $151.1 \pm 46.2$ & $158.7 \pm 47.3$ \\
\hline \%LVEDV & & $100.3 \pm 14.5$ & $163.3 \pm 46.0^{* *}$ \\
\hline
\end{tabular}

Data are the mean \pm SD or the number of patients.

CHD, congenital heart disease; ASD, atrial septal defect; VSD, ventricular septal defect; NT-proBNP, N-terminal prohormone fragment of brain natriuretic peptide; $\mathrm{Qp} / \mathrm{Qs}$, ratio of pulmonary to systemic blood flow; $\mathrm{Pp} / \mathrm{Ps}$, ratio of pulmonary to systemic arterial pressure; Rpl, pulmonary vascular resistance index; RVEDV, right ventricular enddiastolic volume; LVEDV, left ventricular end-diastolic volume.

${ }^{*} \mathrm{P}<0.05$ vs. healthy group, ${ }^{\star *} \mathrm{P}<0.05$ vs. ASD group.

proBNP) found in the circulation are mainly expressed by ventricular cardiac myocytes in response to ventricular volume and pressure overload. ${ }^{15,16}$ However, few reports have described the use of serum cTnI levels for evaluating hemodynamic overload in children with CHD. ${ }^{17}$ Therefore, we hypothesized that significant hemodynamic overload due to a left-to-right shunt can induce myocardial injury. In this study, we measured serum cTnI levels using a highly sensitive assay and compared the levels observed in children with atrial septal defects (ASD) or ventricular septal defects (VSD) to those observed in healthy children without a history of heart disease.

\section{Methods}

\section{Patients and Healthy Volunteer Children}

From November 2005 to May 2010, we prospectively enrolled 412 clinically stable subjects, consisting of 30 children with ASD (ASD group), 32 children with VSD (VSD group) and 350 healthy volunteer children (healthy group). They ranged between 2 months and 16.8 years of age. All of the children in the ASD and VSD groups were admitted to the Department of Pediatrics of Asahikawa Medical University Hospital. We assessed the characteristics of this population, including current medication use and representative parameters that reflected the hemodynamics as examined by cardiac catheterization. The ratio of pulmonary to systemic blood flow (Qp/Qs) was derived by oxymetric measurement with the use of Fick's principle. Also, the ratio of pulmonary to systemic arterial pressure $(\mathrm{Pp} / \mathrm{Ps})$, the pulmonary vascular resistance index $\left(\mathrm{RpI}, \mathrm{WU} / \mathrm{m}^{2}\right)$, the right ventricular end-diastolic volume (RVEDV) and the left ventricular end-diastolic volume (LVEDV) were determined by blood pressure measurement and ventriculography. Deviations in RVEDV and LVEDV from the normal values were calculated as follows:

$$
\begin{aligned}
& \% \text { RVEDV }=\mathrm{RVEDV}^{2}\left(75.1 \times \mathrm{BSA}^{1.43}\right) \times 100 \\
& \% \mathrm{LVEDV}=\mathrm{LVEDV}^{1} /\left(72.5 \times \mathrm{BSA}^{1.43}\right) \times 100
\end{aligned}
$$

where the terms $75.1 \mathrm{BSA}^{1.43}$ and $72.5 \mathrm{BSA}^{1.43}$, which represent normal RVEDV and normal LVEDV, respectively, are a function of the body surface area (BSA) in children with normal hearts. ${ }^{18}$

The children in the healthy group were admitted to an affiliated general hospital between November 2005 and January 2010. When they enrolled in this study, they had fully recovered from either a respiratory tract infection, asthma, or epilepsy after receiving medical treatment.

No children had a history of cardiac ischemia. All of the children and their parents were fully informed about the procedures, risks, and benefits of the study, and written informed consent was obtained before the study. This study was approved by the Ethics Committee of Asahikawa Medical University Hospital.

\section{Measurement of NT-proBNP and cTnl}

Blood samples were taken from the superior vena cava or the antecubital vein. The samples were centrifuged immediately after collection and were subsequently stored at $-21^{\circ} \mathrm{C}$ until being assayed. Serum NT-proBNP levels were measured by an Elecsys 2010 analyzer with a chemiluminescent immunoassay kit (Roche Diagnostics; Mannheim, Germany). Serum cTnI levels were measured by a 3-site sandwich immunoassay technique using an ADVIA Centaur analyzer (TnI-Ultra/ Siemens Medical Solution Diagnostics; Tarrytown, NY, USA). In this assay, the lower limit of detection is $0.002 \mathrm{ng} / \mathrm{ml}$, and the lowest concentration at which the coefficient of variation (CV) was $<10 \%$ was $0.03 \mathrm{ng} / \mathrm{ml}$ and the $\% \mathrm{CV}$ was 4.82. ${ }^{19}$ Further details are available in previously published reports. ${ }^{10,11,20}$

\section{Statistical Analysis}

A least-squares regression line was fitted to the cTnI level vs. age plots for the healthy group. The Spearman's rank correlation coefficient was calculated to assess the correlations between various parameters. We used the Kruskal-Wallis analysis of variance (ANOVA), a non-parametric method, to examine overall differences between the healthy, ASD, and VSD groups because the cTnI levels and the composition of the 3 groups were not always distributed normally. If ANOVA findings were found to be statistically significant, then the statistical significance of the differences between the groups was estimated using the Steel-Dwass test. A multi- 


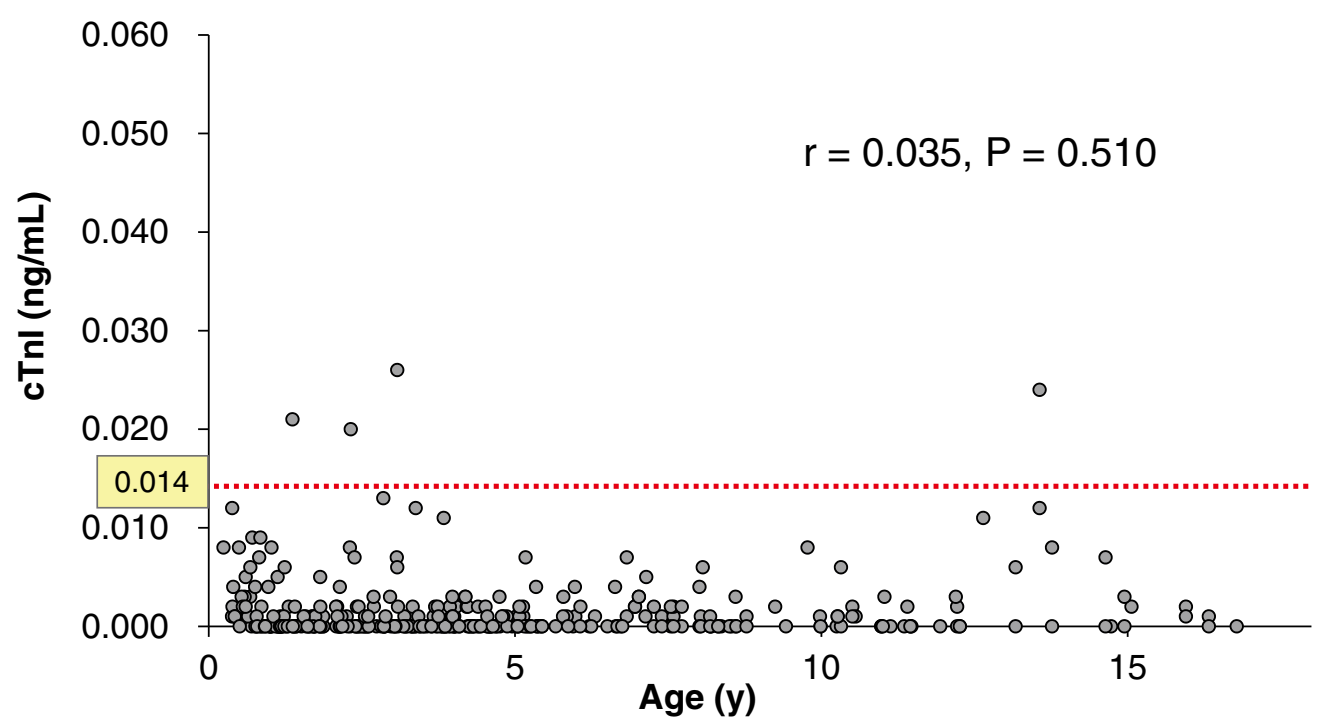

Figure 1. Relationship between cTnl levels and age in the healthy group ( 2 months to 16 years of age, $n=350$ ). The broken line indicates the $99^{\text {th }}$ percentile limit in the distribution of the healthy group $(0.014 \mathrm{ng} / \mathrm{ml})$. cThl, cardiac troponin $\mathrm{l}$.

variate stepwise linear regression analysis was performed to test the effects of age and hemodynamic load on serum cTnI levels. Correlations between continuously distributed variables were tested by linear regression analysis. A P value $<0.05$ was considered to be statistically significant. All statistical analyses were performed with the use of a commercially available statistical software package (SPSS for Windows, Version 18.0).

\section{Results}

The characteristics of the children in the 3 groups are shown in Table 1 . The mean age in the VSD group was significantly lower than that in the healthy group $(\mathrm{P}<0.05)$. The mean NT-proBNP level in the VSD group was significantly higher than that in the healthy and ASD groups $(\mathrm{P}<0.05)$. Six children $(20.0 \%)$ in the ASD group and 27 children (84.3\%) in the VSD group received diuretics at the time of enrollment in this study, but no one received a cardiac medication such as digoxin or $\beta$-blockers.

The Qp/Qs ratios in the ASD and VSD groups $(2.3 \pm 1.0$ and $2.4 \pm 1.1$, respectively) were not significantly different. The $\mathrm{Pp} / \mathrm{Ps}$ ratio and $\mathrm{RpI}$ in the VSD group were significantly higher than those in the ASD group $(\mathrm{P}<0.05$ and $\mathrm{P}<0.05$, respectively). There was no significant difference in $\% \mathrm{RVEDV}$ between the ASD and VSD groups $(151.1 \pm 46.2 \%$ and $158.7 \pm$ $47.3 \%$, respectively). The mean \%LVEDV in the VSD group $(163.3 \pm 46.0 \%)$ was significantly higher than that in the ASD group $(100.3 \pm 14.5 \%)$.

Figure 1 shows the relationship between the serum cTnI level and age in the healthy group (aged 2 months to 16.8 years). cTnI levels were relatively constant with respect to age. A diagnostic threshold for cTnI that was indicative of an abnormal condition was chosen to be the $99^{\text {th }}$ percentile cutoff in the healthy group. The value of this threshold was determined to be $0.014 \mathrm{ng} / \mathrm{ml}$, which was higher by 1 order of magnitude than the minimum quantity that could be measured by the cTnI assay used in this study.

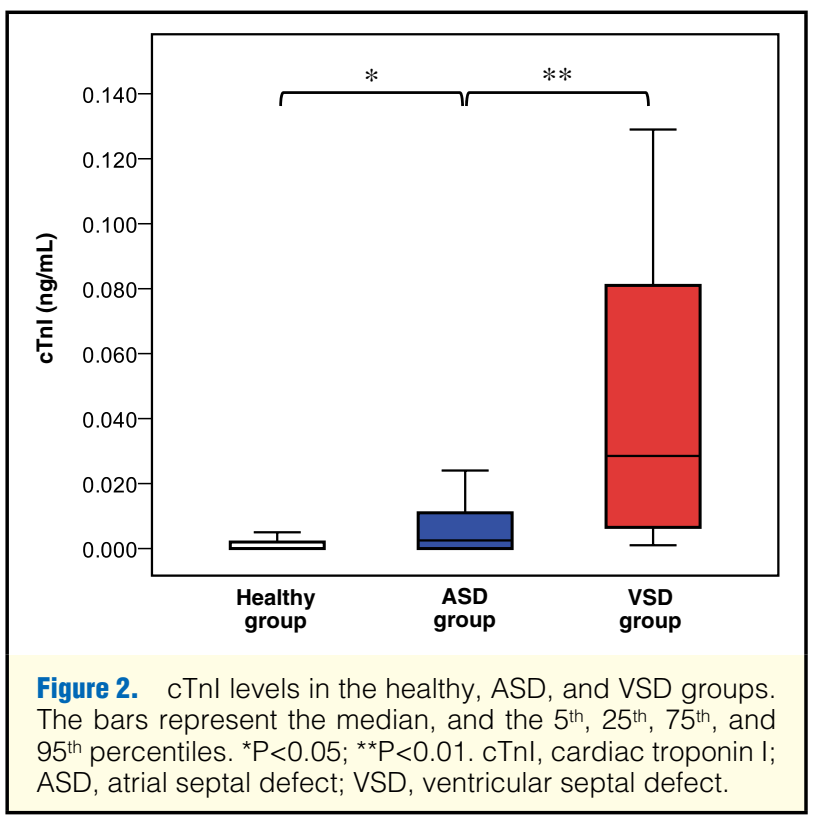

\begin{tabular}{|c|c|c|c|c|}
\hline \multirow[t]{3}{*}{$\begin{array}{r}\text { Table 2. Ur } \\
\text { in }\end{array}$} & \multicolumn{4}{|c|}{$\begin{array}{l}\text { Univariate and Multivariate Analyses of cTnl Levels: } \\
\text { Comparison of Age and Hemodynamic Parameters } \\
\text { in the VSD Group }\end{array}$} \\
\hline & \multicolumn{2}{|c|}{ Univariate analysis } & \multicolumn{2}{|c|}{ Multivariate analysis } \\
\hline & $\mathbf{r}$ & $P$ value & SE & $P$ value \\
\hline Age & -0.522 & 0.001 & & \\
\hline Qp/Qs & 0.571 & $<0.001$ & & \\
\hline $\mathrm{Pp} / \mathrm{Ps}$ & 0.745 & $<0.001$ & 0.745 & $<0.001$ \\
\hline Rpl & 0.309 & 0.043 & & \\
\hline \%RVEDV & 0.553 & 0.001 & & \\
\hline \%LVEDV & 0.066 & 0.359 & & \\
\hline
\end{tabular}

cTnl, cardiac troponin I; SE, standardized partial regression coefficient. Other abbreviations see in Table 1. 


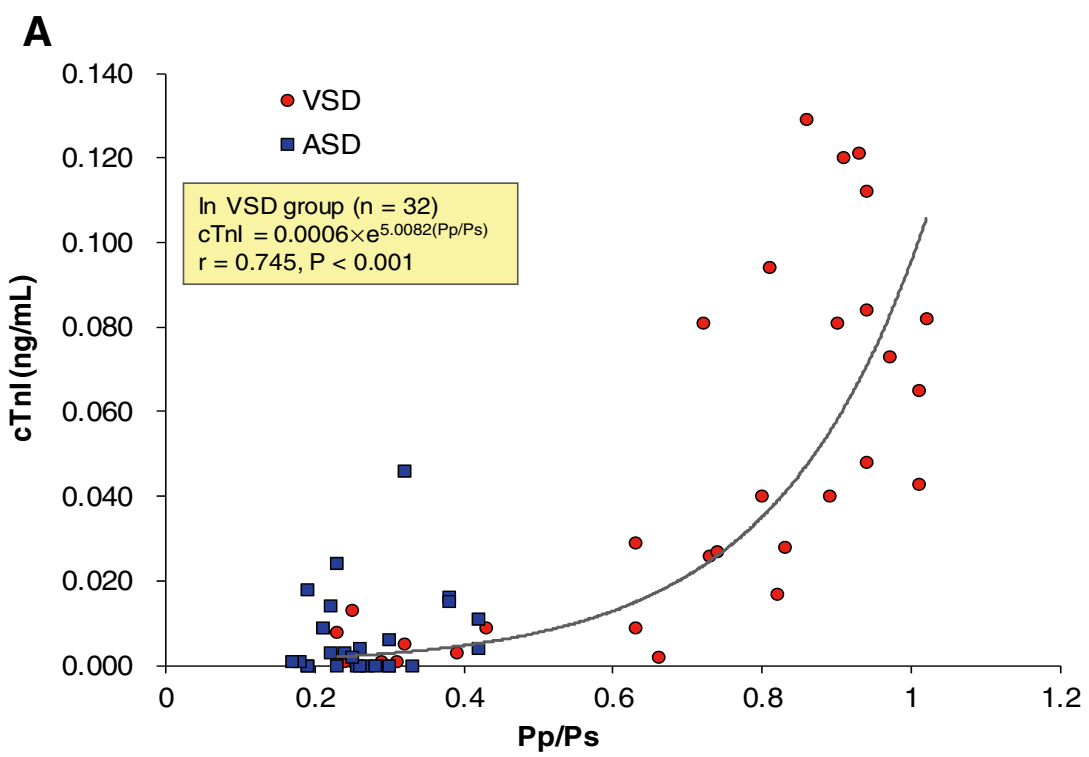

B

\section{C}
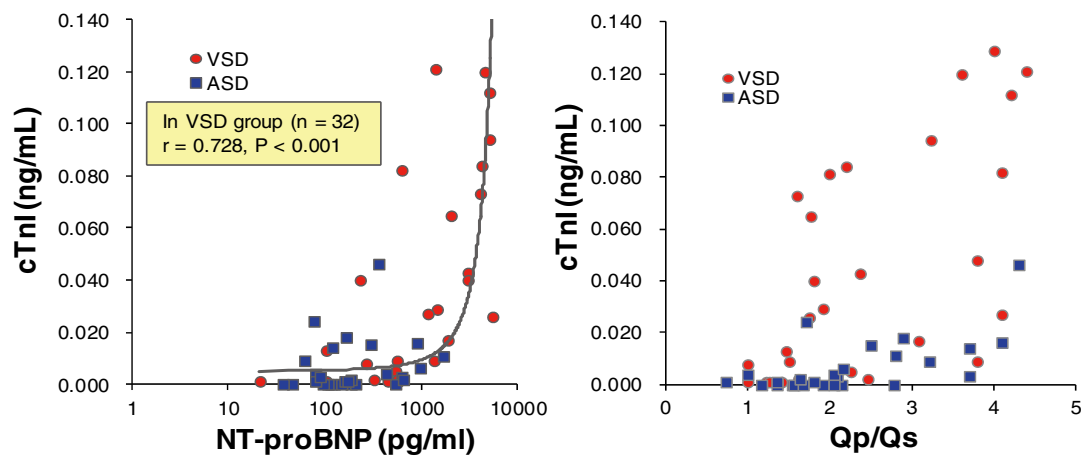

D

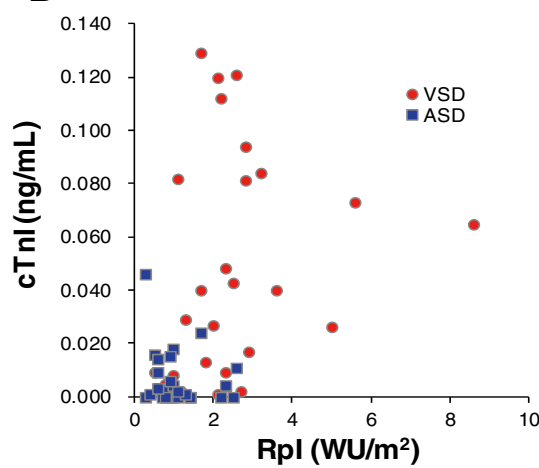

$\mathbf{F}$

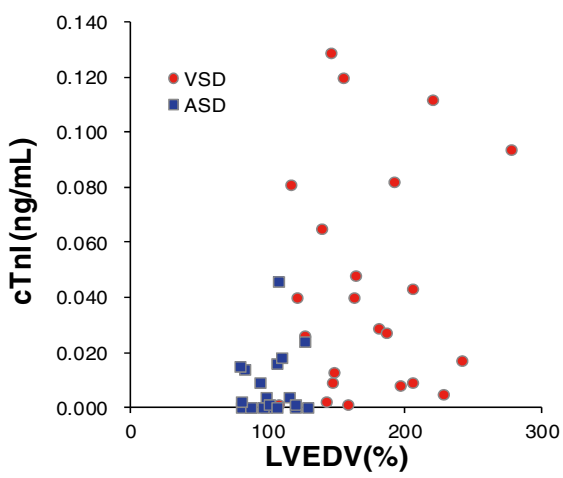

E

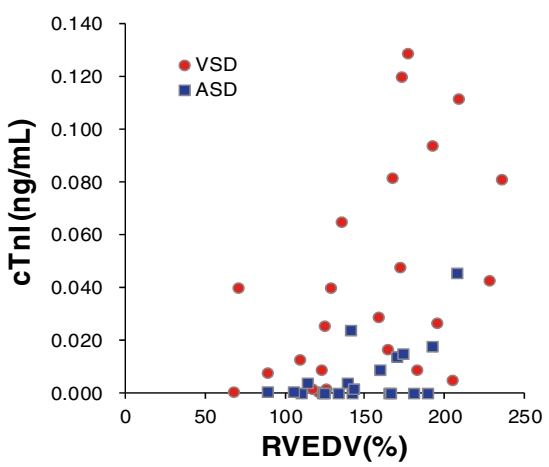

Figure 3. Relationship between cTnl levels and Pp/Ps (A), NT-proBNP (B), Qp/Qs (C), Rpl (D), RVEDV (E), LVEDV (F) in VSD (closed circles, $n=32$ ) and ASD groups (open boxes, $n=30$ ). cTnl, cardiac troponin I; ASD, atrial septal defect; VSD, ventricular septal defect; Pp/Ps, ratio of pulmonary to systemic arterial pressure; NT-proBNP, N-terminal prohormone fragment of brain natriuretic peptide; $\mathrm{Qp} / \mathrm{Qs}$, ratio of pulmonary to systemic blood flow; Rpl, pulmonary vascular resistance index; RVEDV, right ventricular end-diastolic volume; LVEDV, left ventricular end-diastolic volume. 
Figure 2 shows the cTnI levels in the 3 groups. The differences in the cTnI levels between the ASD and healthy groups and between the VSD and ASD groups were significant $\left(\mathrm{P}<0.05\right.$ and $\mathrm{P}<0.01$, respectively). The median $\left(25^{\text {th }}\right.$ $75^{\text {th }}$ percentiles) cTnI level in the VSD group was significantly higher than those in the healthy and ASD groups $[0.029 \mathrm{ng} / \mathrm{ml}(0.008-0.081), 0.000(0.000-0.002)$ and 0.002 (0.000-0.009) respectively].

Table 2 shows the results of univariate and multivariate analyses of the effects of age and hemodynamic parameters on the serum cTnI level in the VSD group. In stepwise multivariate analyses, the serum cTnI level correlated only with the corresponding $\mathrm{Pp} / \mathrm{Ps}$ as a statistically significant independent predictor $(\mathrm{P}<0.001)$. This analysis was highly accurate $(\mathrm{r}=0.745$, ANOVA $\mathrm{P}<0.001)$, the Durbin - Watson ratio (2.534) was acceptable, and there was no other parameter for which the predicted value was beyond \pm 3 SD.

The relationship between the serum cTnI level and Pp/Ps in the VSD and ASD groups is shown in Figure 3A. In the VSD group, cTnI levels significantly correlated with $\mathrm{Pp} / \mathrm{Ps}$ levels $\left[\mathrm{cTnI}=0.0006 \times \mathrm{e}^{5.0082(\mathrm{Pp} / \mathrm{Ps})}(\mathrm{r}=0.745, \mathrm{n}=32, \mathrm{P}<\right.$ 0.001)]. The relationship between the serum cTnI level and other parameters in the VSD and ASD groups are shown in Figures 3B-F.

\section{Discussion}

This study evaluated serum cTnI levels in healthy children and children with CHD, and is the first to show an increased serum cTnI level in children with CHD. The cTnI levels in pediatric patients with ASD and VSD were significantly higher than those in healthy children. In particular, patients with VSD had significantly elevated cTnI levels that were related to pulmonary hypertension. Furthermore, we determined a clinically relevant threshold for the serum cTnI level that can be used to identify myocardial injury in a pediatric population.

In recent years, atrial natriuretic peptide and $\mathrm{BNP}$ have been used as clinical markers for the evaluation of heart failure. ${ }^{21-23}$ In particular, in our previous study, we established that the serum NT-proBNP level is a marker of congestive heart failure in children. ${ }^{24}$ In contrast, cTnT and cTnI are clinical markers of myocardial injury and are associated with a variety of heart abnormalities such as hypertension, cardiomyopathy, myocarditis, myocardial necrosis, and apoptosis. ${ }^{3,5,7,9}$ In addition to its usefulness as a marker of myocardial injury, an increase in circulating cTnI levels correlates with the severity of heart failure. ${ }^{23,25,26}$

A highly sensitive and specific cTnI assay has been developed to detect very low levels of $\mathrm{cTnI},{ }^{11}$ even trace leakages from the unbound cytosolic pool in the circulation. ${ }^{27}$ Such low serum cTnI levels might reflect early myocardial cell death as well as reversible injury, ${ }^{28}$ including transient damage after strenuous endurance exercise. ${ }^{29}$ Thus, the cTnI assay is a very useful tool for detecting subclinical heart disease at the initial presentation in hospitals and for evaluating the severity of cardiac decompensation in emergency cases. ${ }^{30,31}$

Hemodynamic overload in the ASD group was attributable only to right heart volume overload. However, hemodynamic overload in the VSD group included not only volume overload but also right ventricular pressure overload. As a result of Figure 1, we consider that age would not affect the level of cTnI in ASD and VSD groups as well as in the control group. In this study, there was a significant difference in the cTnI levels between the ASD and healthy groups, which suggests that a volume overload can cause myocardial injury. Furthermore, the finding of a significantly increased cTnI level in the VSD group suggests that a ventricular pressure overload, in addition to volume overload, apparently induces myocardial injury.

In experimental models, angiotensin II has been reported to induce necrosis and apoptosis of neonatal and adult ventricular myocardial cells. ${ }^{32,33}$ Another factor, catecholamine, secreted at the time of congestive heart failure might contribute to myocardial injury. ${ }^{34} \mathrm{We}$ did not measure the blood levels of angiotensins or catecholamines in this study because of the difficulty of taking blood for plasma in this population. However, these mechanisms could account for the increase in cTnI levels observed in the enrolled children with CHD.

In the clinical setting, it has been found that serum cTnI levels are increased in patients with non-ischemic heart disease or those without heart failure. cTnI levels are elevated in $75 \%$ of patients who are treated in intensive care units for sepsis or systemic inflammatory response syndrome. ${ }^{35}$ The elements of systemic inflammation including tumor necrosis factor alpha, interleukin 6 and reactive oxygen species might lead to direct myocardial injury through an immunological reaction. ${ }^{27}$ In addition, cTnI levels are elevated in up to $40 \%$ of patients with acute pulmonary embolism. ${ }^{36,37}$ It is known that right ventricular pressure overload due to increased pulmonary arterial resistance leads to a decrease in myocardial perfusion and the oxygen supply, which results in right ventricular dysfunction in patients with pulmonary embolism. ${ }^{38}$ In patients with hypertrophic cardiomyopathy (HCM), the cTnI levels were found to be significantly higher in the area where the left ventricular wall was the thickest. ${ }^{39}$ Petersen et al reported that patients with HCM had a reduced myocardial perfusion reserve that was in proportion to the magnitude of hypertrophy. ${ }^{40}$ Both ventricular hypertrophy and myocardial extension due to left-to-right shunting can inhibit myocardial perfusion. An increase in intrawall pressure due to extension can disturb the coronary microcirculation. ${ }^{41}$ In addition, cardiac enlargement as a result of volume overload increases the oxygen demand of the myocardium, which also results in relative hypoperfusion of the myocardium. ${ }^{27}$ In this study, cTnI levels significantly correlated with $\mathrm{Pp} / \mathrm{Ps}$, but not with RpI (Figure 3). cTnI levels of a few patients with idiopathic pulmonary arterial hypertension, not including those in this study, were normal. These results suggest that cTnI reflects not only pulmonary hypertension without the influence of pulmonary arterial resistance but also myocardial stretch due to volume overload. Monasky et al reported that myocardial stretch causes an increase in the phosphorylation of cTnI in rabbits. ${ }^{42}$ Therefore, we speculate that the right ventricular pressure overload and ventricular volume overload in children with VSD synergistically induces myocardial injury associated with myocardial perfusion.

In our previous study, we reported that both volume overload and pressure overload in children with CHD elevated the serum levels of procollagen type III $\mathrm{N}$-terminal peptide, which is a marker of myocardial remodeling. ${ }^{43}$ Myocardial cells are finally differentiated cells and do not have the potential to divide. In addition, the reproduction of myocardial cells from stem cells and progenitor cells is extremely limited. Apoptosis and necrosis of cardiac myocytes results in myocardial remodeling, leading to a decrease in cardiac contractility and heart failure. Our results support the notion that significant pressure overload due to a left-to-right shunt promotes myocardial injury and might eventually cause irreversible myocardial remodeling in children with CHD. 
A strong correlation was observed between the cTnI and NT-proBNP levels ( $r=0.728$; Figure 3 ). This correlation also indicates that myocardial injury is associated with congestive heart failure exaggerated by pressure overload in addition to volume overload in this population. The use of cTnI as a biomarker might aid in the earlier detection of myocardial injury in patients with CHD. Further studies are required to validate the use of cTnI and NT-proBNP as biomarkers of pulmonary hypertension in patients with VSD. And, additional studies involving larger populations are necessary to validate the effectiveness of cTnI monitoring in children with CHD.

\section{Conclusion}

This study clearly demonstrated that the serum cTnI levels in children with ASD and VSD were significantly higher than that in healthy children. These results suggest that significant volume and pressure overload due to a left-to-right shunt induces myocardial injury and might eventually cause irreversible myocardial remodeling in children with CHD. The serum cTnI level is a useful biomarker for evaluating myocardial damage associated with pulmonary hypertension in VSD children.

\section{Study Limitations}

The present study has 2 limitations. Figure 1 shows the relationship between serum cTnI levels and age in the healthy group (from 2 months to 16.8 years of age). The data from children less than 2 months of age were excluded from the overall analyses because Bader et al reported that serum cTnI levels abruptly increase immediately after birth, followed by a gradual decrease in the neonatal period. ${ }^{4}$ Therefore, our results are not representative of infants aged less than 2 months. The second limitation is that the subjects in the VSD group were younger than those in the other 2 groups. This difference is not due to a selection bias because the patients with VSD were diagnosed on average at an earlier age and were surgically treated sooner compared to patients with ASD.

\section{Disclosures}

We hereby confirm that there are no known conflicts of interest associated with this research and there has been no significant financial support for this work that could have influenced its outcome.

\section{References}

1. Antman EM, Tanasijevic MJ, Thompson B, Schactman M, McCabe $\mathrm{CH}$, Cannon $\mathrm{CP}$, et al. Cardiac-specific troponin I levels to predict the risk of mortality in patients with acute coronary syndromes. N Engl J Med 1996; 335: $1342-1349$.

2. Yasuda S, Shimokawa H. Acute myocardial infarction: The enduring challenge for cardiac protection and survival. Circ J 2009; 73: 2000-2008.

3. Bodor GS, Porterfield D, Voss EM, Smith S, Apple FS. Cardiac troponin-I is not expressed in fetal and healthy or diseased adult human skeletal muscle tissue. Clin Chem 1995; 41: 1710-1715.

4. Suleiman MS, Lucchetti V, Caputo M, Angelini GD. Short periods of regional ischaemia and reperfusion provoke release of troponin I from the human hearts. Clin Chim Acta 1999; 284: 25-30.

5. Hamm CW, Ravkilde J, Gerhardt W, Jorgensen P, Peheim E, Ljungdahl $\mathrm{L}$, et al. The prognostic value of serum troponin $\mathrm{T}$ in unstable angina. $N$ Engl J Med 1992; 327: 146-150.

6. Zethelius B, Johnston N, Venge P. Troponin I as a predictor of coronary heart disease and mortality in 70-year-old men: A community-based cohort study. Circulation 2006; 113: 1071-1078.

7. Thygesen K, Alpert JS, White HD, Jaffe AS, Apple FS, Galvani M, et al. Universal definition of myocardial infarction. Circulation 2007; 116: 2634-2653.

8. Alpert JS, Thygesen K, Antman E, Bassand JP. Myocardial infarc- tion redefined--a consensus document of The Joint European Society of Cardiology/American College of Cardiology Committee for the redefinition of myocardial infarction. J Am Coll Cardiol 2000; 36: $959-969$.

9. Missov E, Calzolari C, Pau B. Circulating cardiac troponin I in severe congestive heart failure. Circulation 1997; 96: 2953-2958.

10. Casals G, Filella X, Bedini JL. Evaluation of a new ultrasensitive assay for cardiac troponin I. Clin Biochem 2007; 40: 1406-1413.

11. Melanson SE, Morrow DA, Jarolim P. Earlier detection of myocardial injury in a preliminary evaluation using a new troponin I assay with improved sensitivity. Am J Clin Pathol 2007; 128: 282-286.

12. van de Kerkhof D, Peters B, Scharnhorst V. Performance of the Advia Centaur second-generation troponin assay TnI-Ultra compared with the first-generation cTnI assay. Ann Clin Biochem 2008; 45: $316-317$.

13. Keller T, Zeller T, Peetz D, Tzikas S, Roth A, Czyz E, et al. Sensitive troponin I assay in early diagnosis of acute myocardial infarction. N Engl J Med 2009; 361: 868-877.

14. Reichlin T, Hochholzer W, Bassetti S, Steuer S, Stelzig C, Hartwiger $\mathrm{S}$, et al. Early diagnosis of myocardial infarction with sensitive cardiac troponin assays. N Engl J Med 2009; 361: 858-867.

15. Yoshimura M, Yasue H, Okumura K, Ogawa H, Jougasaki M, Mukoyama M, et al. Different secretion patterns of atrial natriuretic peptide and brain natriuretic peptide in patients with congestive heart failure. Circulation 1993; 87: 464-469.

16. Maeda K, Tsutamoto T, Wada A, Hisanaga T, Kinoshita M. Plasma brain natriuretic peptide as a biochemical marker of high left ventricular end-diastolic pressure in patients with symptomatic left ventricular dysfunction. Am Heart J 1998; 135: 825-832.

17. Shah A, Feraco AM, Harmon C, Tacy T, Fineman JR, Bernstein HS. Usefulness of various plasma biomarkers for diagnosis of heart failure in children with single ventricle physiology. Am J Cardiol 2009; 104: 1280-1284.

18. Nakazawa M, Marks RA, Isabel-Jones J, Jarmakani JM. Right and left ventricular volume characteristics in children with pulmonary stenosis and intact ventricular septum. Circulation 1976; 53: 884890.

19. James S, Flodin M, Johnston N, Lindahl B, Venge P. The antibody configurations of cardiac troponin I assays may determine their clinical performance. Clin Chem 2006; 52: 832-837.

20. Collinson PO, Barnes SC, Gaze DC, Galasko G, Lahiri A, Senior R. Analytical performance of the $\mathrm{N}$ terminal pro $\mathrm{B}$ type natriuretic peptide (NT-proBNP) assay on the Elecsys 1010 and 2010 analysers. Eur J Heart Fail 2004; 6: 365-368.

21. Levin ER, Gardner DG, Samson WK. Natriuretic peptides. N Engl J Med 1998; 339: 321-328.

22. Ohuchi H, Takasugi H, Ohashi H, Okada Y, Yamada O, Ono Y, et al. Stratification of pediatric heart failure on the basis of neurohormonal and cardiac autonomic nervous activities in patients with congenital heart disease. Circulation 2003; 108: 2368-2376.

23. Tang WH, Francis GS, Morrow DA, Newby LK, Cannon CP, Jesse RL, et al. National Academy of Clinical Biochemistry Laboratory Medicine practice guidelines: Clinical utilization of cardiac biomarker testing in heart failure. Circulation 2007; 116: e99-e109.

24. Sugimoto M, Manabe H, Nakau K, Furuya A, Okushima K, Fujiyasu $\mathrm{H}$, et al. The role of N-terminal pro-B-type natriuretic peptide in the diagnosis of congestive heart failure in children: Correlation with the heart failure score and comparison with B-type natriuretic peptide. Circ J 2010; 74: 998-1005.

25. Tsutamoto T, Kawahara C, Nishiyama K, Yamaji M, Fujii M, Yamamoto T, et al. Prognostic role of highly sensitive cardiac troponin I in patients with systolic heart failure. Am Heart J 2010; 159: 63-67.

26. Kuwabara Y, Sato Y, Miyamoto T, Taniguchi R, Matsuoka T, Isoda $\mathrm{K}$, et al. Persistently increased serum concentrations of cardiac troponin in patients with acutely decompensated heart failure are predictive of adverse outcomes. Circ J 2007; 71: 1047-1051.

27. Korff S, Katus HA, Giannitsis E. Differential diagnosis of elevated troponins. Heart 2006; 92: 987-993.

28. Wu AH, Ford L. Release of cardiac troponin in acute coronary syndromes: Ischemia or necrosis? Clin Chim Acta 1999; 284: $161-$ 174.

29. Urhausen A, Scharhag J, Herrmann M, Kindermann W. Clinical significance of increased cardiac troponins $\mathrm{T}$ and $\mathrm{I}$ in participants of ultra-endurance events. Am J Cardiol 2004; 94: 696-698.

30. Saiki A, Iwase M, Takeichi Y, Umeda H, Ishiki R, Inagaki H, et al. Diversity of the elevation of serum cardiac troponin I levels in patients during their first visit to the emergency room. Circ J 2007; 71: $1458-1462$

31. Sato Y, Miyamoto T, Taniguchi R, Nagao K, Matsuoka T, Fukuhara 
$\mathrm{R}$, et al. The clinical and hemodynamic factors that influence the concentrations of biomarkers of myocyte injury measured by high sensitive assay PATHFAST. $J$ Cardiol 2009; 53: 20-27.

32. Tan LB, Jalil JE, Pick R, Janicki JS, Weber KT. Cardiac myocyte necrosis induced by angiotensin II. Circ Res 1991; 69: 11851195.

33. Kajstura J, Cigola E, Malhotra A, Li P, Cheng W, Meggs LG, et al. Angiotensin II induces apoptosis of adult ventricular myocytes in vitro. J Mol Cell Cardiol 1997; 29: 859-870.

34. Mann DL, Kent RL, Parsons B, Cooper G 4th. Adrenergic effects on the biology of the adult mammalian cardiocyte. Circulation 1992; 85: 790-804.

35. John J, Woodward DB, Wang Y, Yan SB, Fisher D, Kinasewitz GT, et al. Troponin-I as a prognosticator of mortality in severe sepsis patients. J Crit Care 2010; 25: 270-275.

36. Konstantinides S, Geibel A, Olschewski M, Kasper W, Hruska N, Jackle $S$, et al. Importance of cardiac troponins I and $\mathrm{T}$ in risk stratification of patients with acute pulmonary embolism. Circulation 2002; 106: $1263-1268$.

37. Kucher N, Wallmann D, Carone A, Windecker S, Meier B, Hess OM. Incremental prognostic value of troponin I and echocardiography in patients with acute pulmonary embolism. Eur Heart $J$ 2003; 24: $1651-1656$.

38. Meyer T, Binder L, Hruska N, Luthe H, Buchwald AB. Cardiac troponin I elevation in acute pulmonary embolism is associated with right ventricular dysfunction. J Am Coll Cardiol 2000; 36: $1632-1636$.

39. Kubo T, Kitaoka H, Okawa M, Yamanaka S, Hirota T, Hoshikawa $\mathrm{E}$, et al. Serum cardiac troponin I is related to increased left ventricular wall thickness, left ventricular dysfunction, and male gender in hypertrophic cardiomyopathy. Clin Cardiol 2010; 33: E1-E7.

40. Petersen SE, Jerosch-Herold M, Hudsmith LE, Robson MD, Francis JM, Doll HA, et al. Evidence for microvascular dysfunction in hypertrophic cardiomyopathy: New insights from multiparametric magnetic resonance imaging. Circulation 2007; 115: 2418-2425.

41. Galderisi M. Epicardial coronary vessels and coronary microcirculation in pressure overload hypertrophy: A complex interaction. Am J Hypertens 2007; 20: 285-286.

42. Monasky MM, Biesiadecki BJ, Janssen PM. Increased phosphorylation of tropomyosin, troponin I, and myosin light chain-2 after stretch in rabbit ventricular myocardium under physiological conditions. J Mol Cell Cardiol 2010; 48: 1023-1028.

43. Sugimoto M, Masutani S, Seki M, Kajino H, Fujieda K, Senzaki H. High serum levels of procollagen type III N-terminal amino peptide in patients with congenital heart disease. Heart 2009; 95: $2023-2028$.

44. Bader D, Kugelman A, Lanir A, Tamir A, Mula E, Riskin A. Cardiac troponin I serum concentrations in newborns: A study and review of the literature. Clin Chim Acta 2006; 371: 61 -65. 